\title{
Influence of brain-derived neurotrophic factor on pathfinding of dentate granule cell axons, the hippocampal mossy fibers Makoto Tamura ${ }^{1}$, Naohiro Tamura ${ }^{1}$, Takamitsu Ikeda ${ }^{1}$, Ryuta Koyama1, Yuji Ikegaya1,2, Norio Matsuki ${ }^{1}$ and Maki K Yamada*1,2
}

\author{
Address: ${ }^{1}$ Laboratory of Chemical Pharmacology, Graduate School of Pharmaceutical Sciences, The University of Tokyo, 7-3-1 Hongo, Bunkyo-ku, \\ 113-0033, Tokyo, Japan and 2PRESTO, JST, Honcho, Kawaguchi-shi, Saitama 332-0012, Japan \\ Email: Makoto Tamura - mtamura44@gmail.com; Naohiro Tamura - how_about_some_cup_of_tea@yahoo.co.jp; \\ Takamitsu Ikeda - ikeda.tk@gmail.com; Ryuta Koyama - rkoyama@mol.f.u-tokyo.ac.jp; Yuji Ikegaya - ikegaya@mol.f.u-tokyo.ac.jp; \\ Norio Matsuki - matsuki@mol.f.u-tokyo.ac.jp; Maki K Yamada* - makiky-tky@umin.ac.jp \\ * Corresponding author
}

Published: 31 January 2009

Molecular Brain 2009, 2:2 doi:10.1186/1756-6606-2-2

This article is available from: http://www.molecularbrain.com/content/2/I/2

(c) 2009 Tamura et al; licensee BioMed Central Ltd.

This is an Open Access article distributed under the terms of the Creative Commons Attribution License (http://creativecommons.org/licenses/by/2.0), which permits unrestricted use, distribution, and reproduction in any medium, provided the original work is properly cited.

\begin{abstract}
Mossy fibers, the dentate granule cell axons, are generated throughout an animal's lifetime. Mossy fiber paths and synapses are primarily restricted to the stratum lucidum within the CA 3 region. Brain-derived neurotrophic factor (BDNF), a neurotrophin family protein that activates Trk neurotrophin receptors, is highly expressed in the stratum lucidum in an activity-dependent manner. The addition of a Trk neurotrophin receptor inhibitor, K252a, to cultured hippocampal slices induced aberrant extension of mossy fibers into ectopic regions. BDNF overexpression in granule cells ameliorated the mossy fiber pathway abnormalities caused by a submaximal dose of K252a. A similar rescue was observed when BDNF was expressed in CA3 pyramidal cells, most notably in mossy fibers distal to the expression site. These findings are the first to clarify the role of BDNF in mossy fiber pathfinding, not as an attractant cue but as a regulator, possibly acting in a paracrine manner. This effect of BDNF may be as a signal for new fibers to fasciculate and extend further to form synapses with neurons that are far from active BDNF-expressing synapses. This mechanism would ensure the emergence of new independent dentate gyrus-CA 3 circuits by the axons of new-born granule cells.
\end{abstract}

\section{Background}

Mossy fibers, which are the dentate granule cell axons, are the only excitatory efferent projections of the hippocampal dentate gyrus, which has a crucial role in certain types of learning and memory. Mossy fibers have several unique features. Each mossy fiber forms extraordinarily large synapses with the proximal apical dendrites of only 11 to 18 pyramidal cells in the CA3 region [1]; further, the action potentials of a single granule cell are strong enough to discharge its target neurons. Importantly, granule cells are continuously produced, even in adulthood [2], and newly formed granule cells in the adult brain are more likely to be recruited into circuits related to spatial memory than existing granule cells [3]. Thus, mossy fibers from newly formed granule cells are likely influenced by neuronal activity. Elucidation of the neuronal activity-related nature of these fibers, therefore, may provide clues to the raison d'etre of these peculiar axons and dentate granule cells. 
Mossy fibers bundle tightly together and extend into a narrow region of the CA3 region called the stratum lucidum (SL), where they form synapses with CA3 pyramidal cells. Inhibition of Trk neurotrophin receptors and the Trk downstream molecule mitogen-activated protein (MAP) kinase kinase (MEK) disrupts mossy fiber pathfinding [4]. The Trk receptors, TrkA, TrkB, and TrkC, are primarily activated by nerve growth factor (NGF), brain-derived neurotrophic factor (BDNF), and neurotrophin-3, respectively. Because the highest BDNF protein levels in the brain are found along the pathway from the dentate hilus to the SL $[5,6], \mathrm{BDNF}$ is the candidate molecule most likely to be involved in regulating mossy fiber pathfinding. Moreover, the activity-dependence of BDNF biosynthesis and secretion $[7,8]$. raises the interesting possibility that BDNF mediates the interaction between active and newlyformed BDNF-expressing neuronal circuits.

Several studies have focused on BDNF-induced abnormalities in mossy fiber sprouting, which may be one etiology of temporal lobe epilepsy. BDNF, which is highly upregulated in some hyperactivity conditions, may $[9,10]$ or may not $[11,12]$ induce mossy fiber sprouting [13]. The role of BDNF in mossy fiber pathfinding under normal conditions remains to be elucidated.

To investigate the role of BDNF in healthy mossy fiber formation, we applied the broad-spectrum Trk neurotrophin receptor inhibitor K252a in combination with local BDNF gene expression induced with a lentivirus, which produced moderate and physiologic levels of BDNF. This combined molecular and pharmacologic approach allowed us to selectively examine effects of BDNF that may be overlooked with simple loss-of-function experiments, given the potential for redundancy between BDNF and NGF within the SL.

\section{Results}

\section{Gene expression and development of an assay system for tracking mossy fiber pathfinding}

A neuron-specific $\alpha$-calmodulin-dependent protein kinase II (CaMKII) promoter was used for all expression experiments [14]. The lentivirus suspension, which expresses enhanced green fluorescent protein (EGFP), was locally introduced at 2 or 3 sites in the granule cell layer in hippocampal slices; almost all cells expressing EGFP were granule cells, based on their cellular morphology and localization in the granule cell layer (Fig. 1A and 1B, Fig. 2C and 2D). The mossy fiber pathways could be specifically and clearly visualized by this method (Fig. 1BD). At 8 days in vitro (DIV), EGFP-expressing mossy fibers in the control slices were generally restricted to the normal path, the SL (Fig. 1C). In K252a-treated slices, however, mossy fibers were abnormally distributed outside the SL in both the CA3c and CA3a areas (Fig. 1D). In these slices, the EGFP signal intensity was decreased in the SL and increased in subregions other than the SL (Fig. 1E and 1F). These data indicated that our new assay system was able to produce and detect the aberrant mossy fiber growth induced by K252a that was reported previously [4].

\section{Co-expression of BDNF and Venus using the P2A peptide}

Mossy fiber pathways in the cultured hippocampal slices were rich in BDNF (Additional file 1), consistent with previous findings in brain sections [15]. Thus, BDNF was selected from among candidate molecules whose signals are attenuated by K252a. BDNF overexpression was induced by lentivirus-mediated gene transfer to determine whether the effects of a submaximal dose of K252a could be attenuated. To identify cells overexpressing BDNF, we co-expressed Venus, a GFP variant, using a self-cleaving 2A sequence derived from picornavirus (P2A). Through a ribosomal "skip" mechanism, the $\mathrm{P} 2 \mathrm{~A}$ peptide interconnecting two different proteins spontaneously cleaves, thereby separating the proteins and theoretically producing equivalent amounts of both proteins [16].

A Venus-P2A-BDNF sequence was constructed by inserting the P2A sequence between the Venus and BDNF sequences. Distinct expression of BDNF and Venus was confirmed by immunoblotting analysis of HEK293T cell lysates transfected with the Venus-P2A-BDNF construct. We confirmed that the expressed BDNF in the HEK293T cells was secreted into the culture medium (Fig. 2A).

The BDNF expression levels produced in the cultured slices using this virus were similar to the BDNF levels that are endogenously expressed and accumulated, and were visualized as punctate staining (Fig. 2B-F). We did not observe the growth of any aberrant basal dendrites or axonal branches as has previously been observed in BDNF-overexpressing cells produced using a Gene gun [17]; this discrepancy may be due to the fact that our experimental system produced close to physiologic levels of BDNF expression.

\section{BDNF-overexpressing mossy fibers find normal pathways in the presence of a submaximal dose of $K 252 a$}

In the expression experiments, 4 days after transfection, preexisting mossy fibers were cut at a site proximal to the CA3 region (dotted lines in Fig. 3), and the paths of newly extended fibers expressing Venus were observed, because substantial BDNF expression was obtained by 4 DIV (data not shown). A 7-day K252a treatment was initiated soon after the incision. In the control (nonK252a-treated) slices, the Venus-labeled mossy fibers normally reextended to and within the SL 7 days after the fibers were cut (Fig. 3A). While treatment with low dose (100 nM) of K252a was enough to defasciculate mossy fibers in the ectopic subregions (Fig. 3B), similar to that shown in Fig- 
A
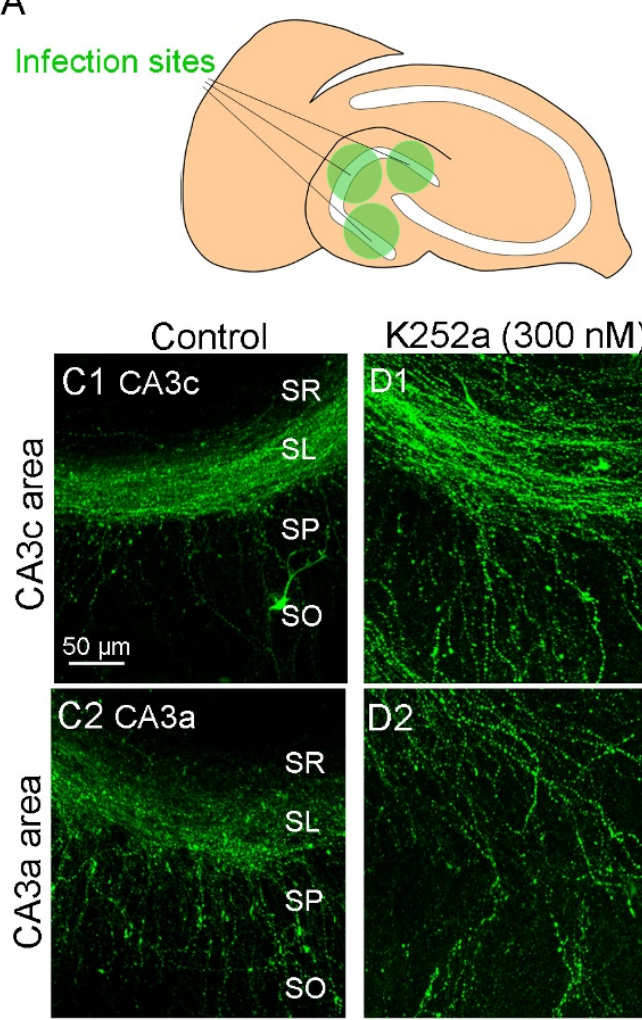

$\mathrm{K} 252 \mathrm{a}(300 \mathrm{nM})$
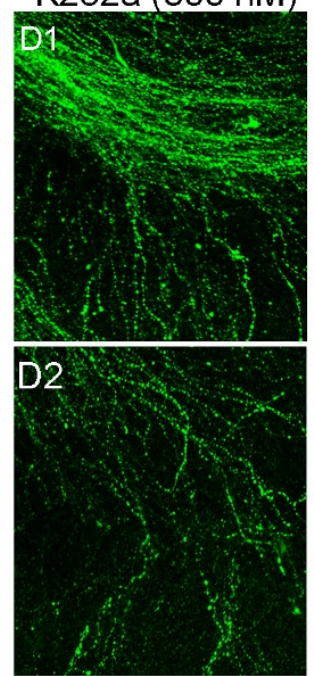
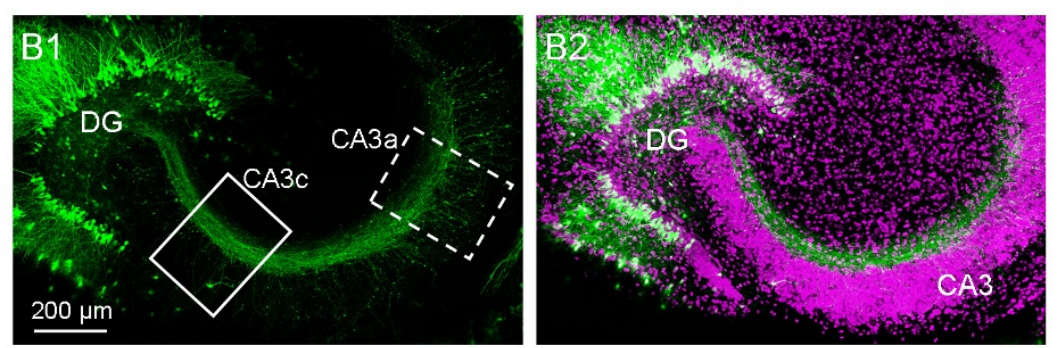

$\mathrm{E}$

$\mathrm{CA} 3 \mathrm{c}$ area
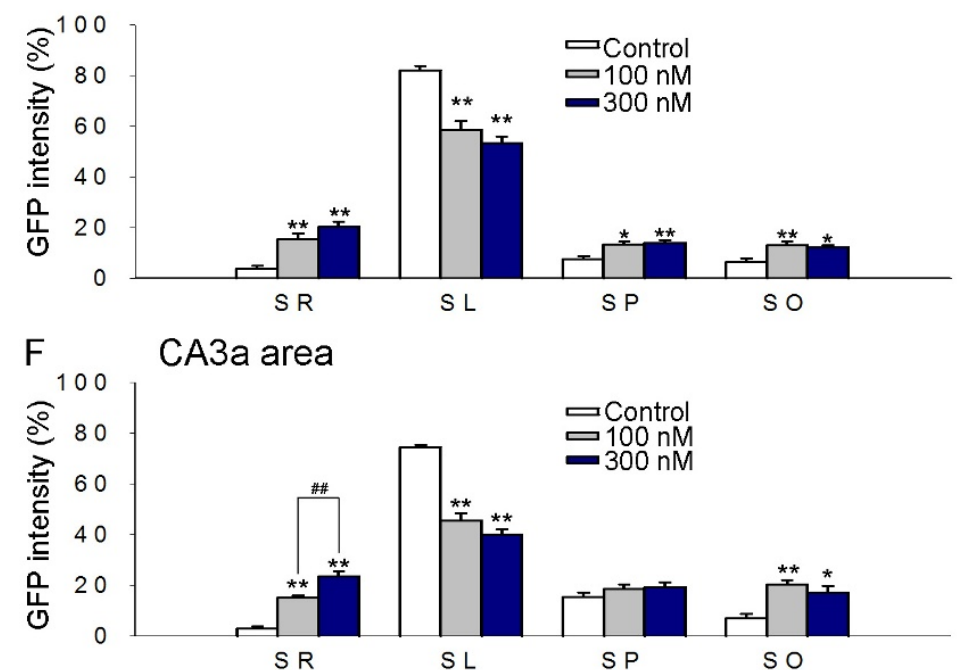

CA3a area

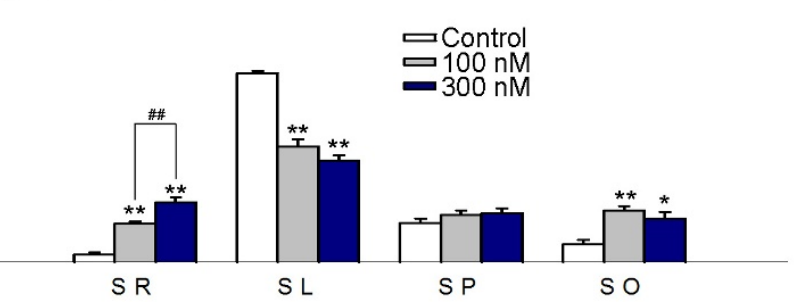

Figure I

A novel approach for visualizing mossy fibers in cultured hippocampal slices. (A) A schematic diagram of locally introduced lentiviral vectors. Lentivirus, which induces the expression of enhanced GFP (EGFP) under the influence of a CaMKII promoter, was injected into 2 or 3 sites of the granule cell layer in hippocampal slices. (B) Representative images of the results. Granule cells specifically expressed EGFP. Green: EGFP immunoreactivity, Magenta: Nissl staining of the neurons. (C and D) Images of control slices (C) and slices treated with $\mathrm{K} 252 \mathrm{a}(300 \mathrm{nM})(\mathrm{D})$ in the $\mathrm{CA} 3 \mathrm{c}(\mathrm{Cl}$, solid box in $\mathrm{BI})$ and CA3a $(\mathrm{C} 2$, dotted box in $\mathrm{BI})$ areas. Mossy fibers in control slices $(\mathrm{C})$ were observed primarily in the SL, similar to what was observed in vivo, while those in the K252a-treated slices were abnormally distributed outside of the SL as shown in D. (E and F) Distribution of the mossy fibers treated by 100 and $300 \mathrm{nM}$ of K252a as assessed by the measurement of EGFP intensity in the CA3c $(E)$ and CA3a $(F)$ areas. $* P<0.05$ and $\# \#, * * P<0.01$; Tukey's test after analysis of variance $(n=7-9$ slices obtained from 4 independent experiments). DG: dentate gyrus, SR: stratum radiatum, SP: stratum pyramidale, and SO: stratum oriens.

ure 1, BDNF-overexpressing mossy fibers extended to the SL (Fig. 3C), similar to that observed in control (nonK252a-treated) slices (Fig. 3D and 3E).

In order to determine the dose-response relationship between the concentration of K252a and the action of BDNF, we performed the same experiments with increasing doses of K252a. We observed that the slices treated with higher concentrations of K252a (200 nM and 300 $\mathrm{nM}$ ) were rarely affected by BDNF expression (Additional file 2).

These findings indicate that BDNF secreted by granule cells (mossy fibers) supports normal mossy fiber pathfinding.
BDNF overexpression in CA3 pyramidal cells also rescues abnormal mossy fiber projection

To determine the possible site and mode of BDNF action, we investigated whether BDNF overexpressed by CA3 pyramidal cells also regulates mossy fiber pathfinding. Visualization of mossy fibers using biocytin (Fig. 4A and, $4 \mathrm{~B})$ confirmed the presence of misguided and defasciculated fibers in the K252a-treated slices (Fig. 4C). In the presence of $\mathrm{K} 252 \mathrm{a}$, when BDNF-carrying viruses were injected in the $\mathrm{CA} 3 \mathrm{~b}$ area at the middle of the $\mathrm{CA} 3$ region, mossy fibers extended beyond the CA3b area to the more distal CA3a area and the paths gradually bundled within the SL (Fig. 4D-F). 


\section{A Separate expression of Venus-P2A-BDNF} A1 Cell lysate / anti-Venus
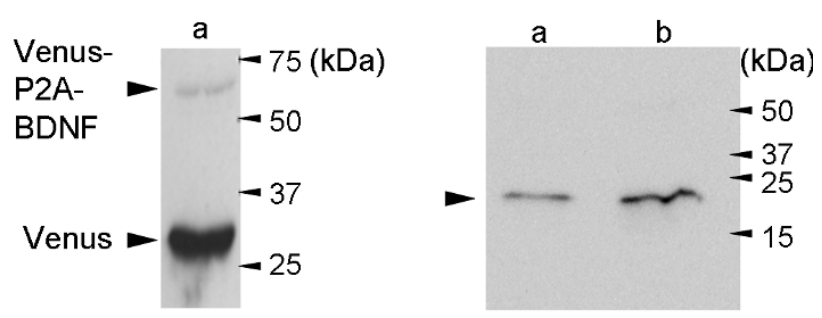

a: CMV-driven Venus-P2A-BDNF b: CMV-driven BDNF
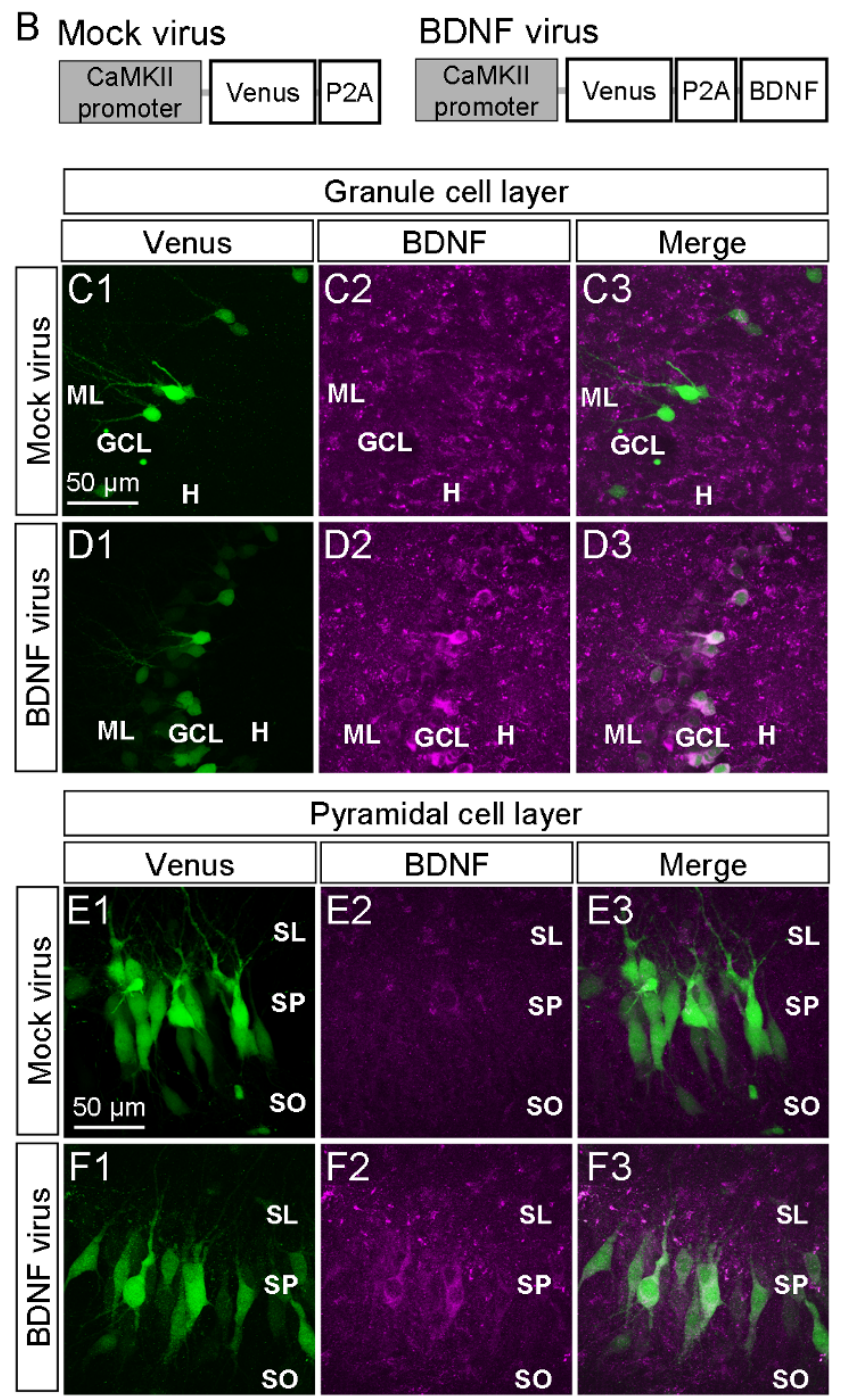

Figure 2

\section{Figure 2}

Co-expression of BDNF and Venus using P2A pep-

tide. (A) Protein expression with the Venus-P2A-BDNF construct, which was designed to produce Venus-P2A fusion protein and BDNF separately, was confirmed by performing an immunoblotting analysis for Venus, a GFP mutant, $(A I)$ or BDNF (A2). In this experiment, the Venus-P2A-BDNF construct was transfected to HEK293T. Even though a weak band was noted at the position of the non-cleaved fusion protein for Venus-P2A-BDNF, almost all signals were detected for the cleaved Venus-P2A. (A2) In the culture medium of HEK293 cells transfected with the Venus-P2ABDNF construct (lane a), a specific band was observed at the same molecular weight as that for the control from cells showing BDNF expression (lane $b$ ); this indicated that BDNF, when cleaved from the Venus-P2A-BDNF construct, followed the normal course of processing and secretion. (B) Schematic diagrams of the expression vectors. (C-F) Immunohistochemical staining for Venus (green) and BDNF (magenta) in the dentate gyrus $(C, D)$ and $C A 3$ region $(E, F)$ of cultured slices transfected with the mock Venus-P2A- (C, E) or Venus-P2A-BDNF-carrying (D, F) virus. In D and $F$, Venus-positive cells showed intense BDNF staining in slices transfected with the Venus-P2A-BDNF virus, whereas endogenous BDNF and Venus were rarely colocalized in slices transfected with the mock virus ( $C$ and $E$ ). ML: molecular layer, GCL: granule cell layer, DH: dentate hilus, SL: stratum lucidum, SP: stratum pyramidale, and SO: stratum oriens.

Structures like presynaptic varicosities were observed in the labeled mossy fibers. It is noteworthy, however, that the passing fibers did not form obvious varicosities on any BDNF-expressing CA3 neurons (Fig. 4D).

\section{Discussion}

In this study, we used a combined molecular and pharmacologic approach to examine the effect of BDNF on hippocampal mossy fiber pathfinding. Rat brain hippocampal slices that included the CA3 region were treated with a noncompetitive inhibitor of tyrosine kinase activity of Trk receptors, K252a [18], combined with lentiviral vector-induced BDNF overexpression in either granule cells or pyramidal cells. K252a, which was used to inhibit the possible action of neurotrophin receptors, was used at a submaximal dose (Fig. 1D and Additional file 2) and is thus considered to act partially, allowing for the remaining receptors to be activated by the expressed BDNF. The results indicated that the overexpressed BDNF in both types of cells rescued the K252a-induced abnormal mossy fiber pathfinding.

BDNF is a neurotrophin that activates the Trk receptor family, and other neurotrophins are suggested to have compensatory roles [19]. Therefore, although BDNF-defi- 

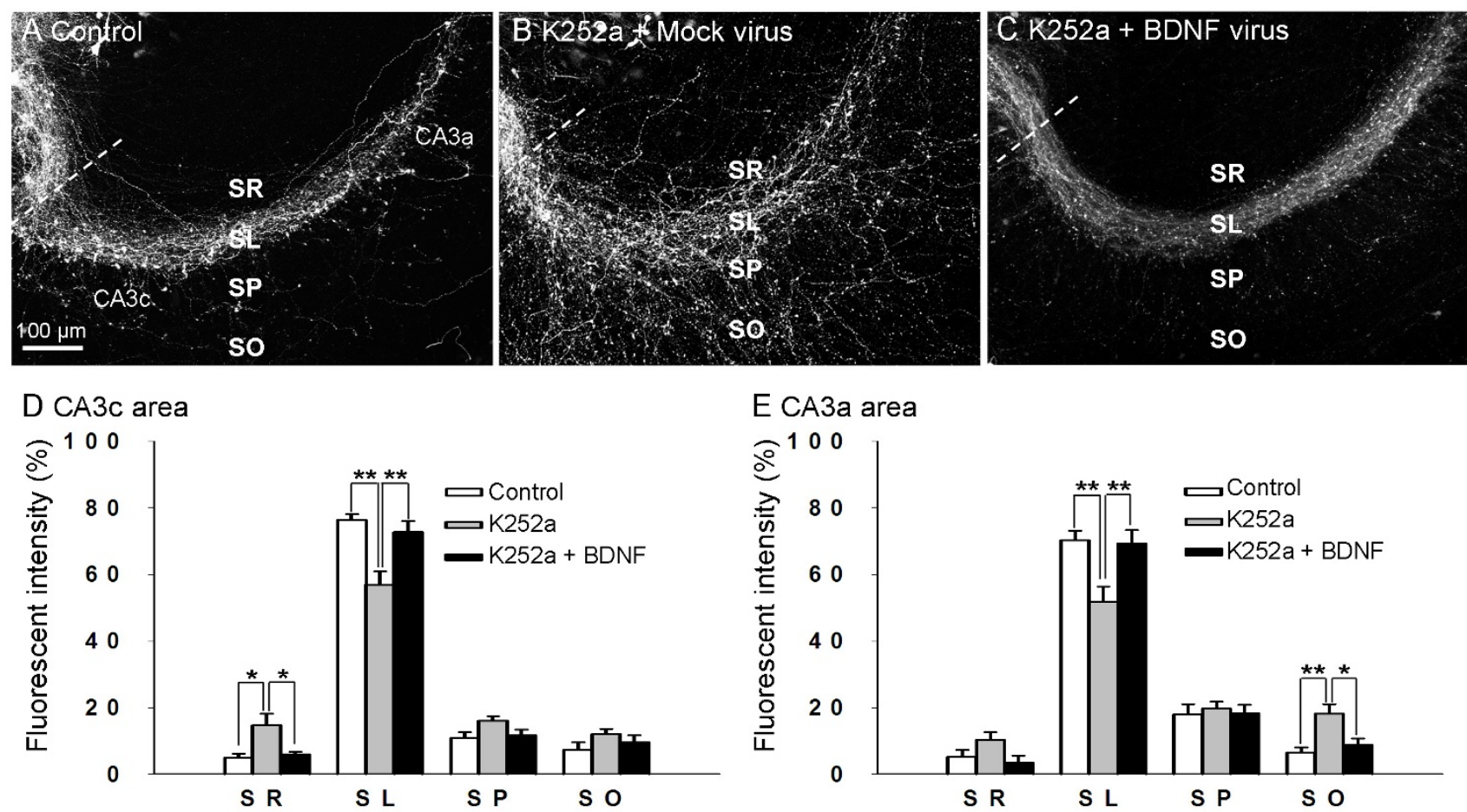

Figure 3

BDNF expressed in granule cells rescued the aberrant mossy fiber extension induced by a submaximal dose of K252a ( 100 nM). (A-C) Compared with control slices (A), K252a-treated slices infected with mock viruses showed an abnormal distribution of mossy fibers (B). Meanwhile, the BDNF-expressing mossy fibers extended into the SL (C) in a manner similar to that observed in the control slices. The dotted line indicates the incision line made 4 days after transfection to adjust the axonal extension to the expression of proteins. ( $D$ and $E$ ) Mossy fiber distribution analyzed by a ratio distribution of the coexpressed Venus in the CA3c (D) and CA3a (E) areas. $* p<0.05$ and $* * P<0.01$; Tukey's test after analysis of variance $(n=7-9$ slices obtained from 4 independent experiments). SR: stratum radiatum, SP: stratum pyramidale, and SO: stratum oriens.

cient mice have normal mossy fiber paths (Tamura et al., unpublished observation) and TrkB-deficient mice do not show aberrant defasciculation of mossy fibers [20], BDNF may still be critical for mossy fiber pathfinding because other neurotrophins, such as NGF, that are also expressed in the mossy fiber pathways [20], may apparently compensate for the lack of BDNF signaling.

Experiments with pharmacologic inhibitors sometimes overcome functional redundancy in molecules. In addition, gene expression (of BDNF in this case) is a powerful method to confirm the specificity of molecular participants compared to pharmacologic treatment. In the present study, a novel combination of pharmacologic and molecular expression approaches was developed to elucidate the function of a molecule that may have otherwise remained hidden due to redundancy. Although rescue experiments using multiple gene-deficient mice, as reported previously [21], may be more powerful, the use of the present combined molecular and pharmacologic approach demonstrated for the first time that BDNF influ- ences mossy fiber pathfinding. A similar combinatorial approach may be a useful first step toward examining the biologic functions of molecules within a family.

Although BDNF functions as a chemoattractant for various neurons, including Xenopus spinal neurons, rat cerebellar neurons, and chick retinal ganglion neurons [22$24]$, the present findings in the hippocampus were not consistent with a chemoattractant function of BDNF for the following reasons. First, BDNF produced within the guided axons was sufficient to regulate their paths (Fig. 3); and second, when BDNF was expressed in CA3 pyramidal cells, the fibers did not target the cells in which BDNF was overexpressed, but rather gradually became fasciculated after they passed through the region of cells overexpressing BDNF (Fig.4). BDNF may instead affect the expression and/or activation of cell adhesion molecules that form mossy fiber bundles with one another and/or bind to the proximal dendrites of CA3 pyramidal cells. Reports showing that BDNF mediates cadherin-catenin interactions in dissociated hippocampal neurons and that some types of 

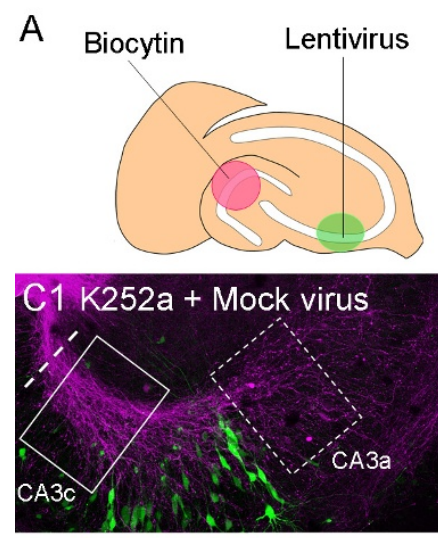

D1 K252a + BDNF virus
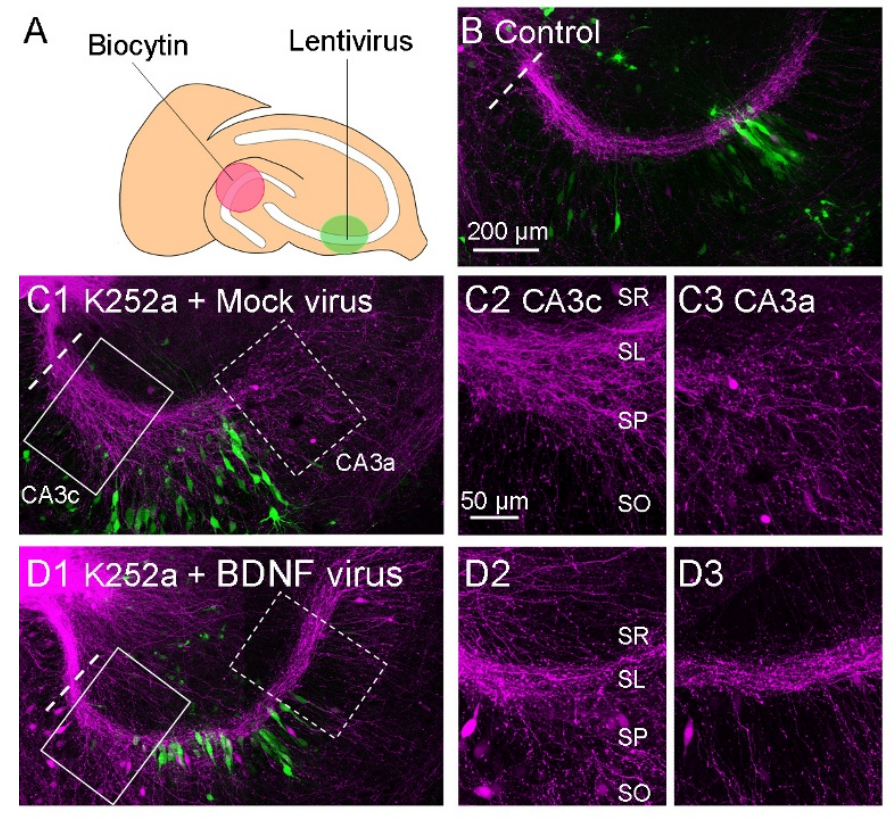

\section{E CA3c area}

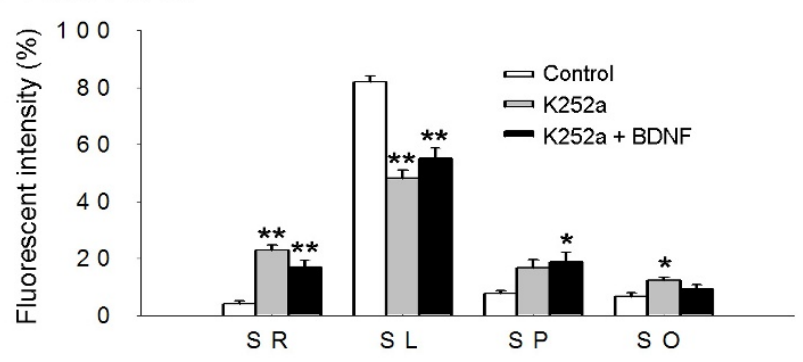

F CA3a area

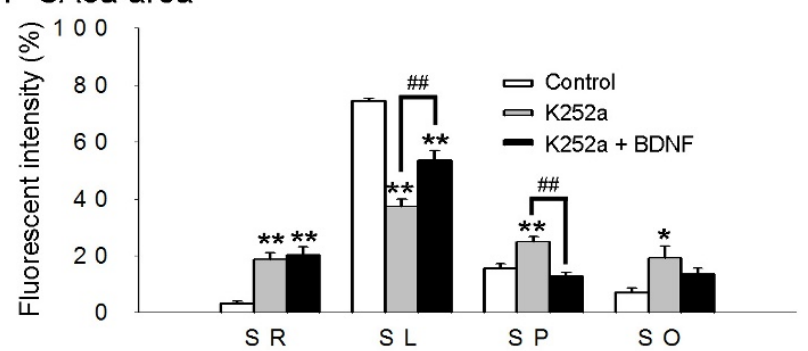

\section{Figure 4}

Overexpression of BDNF in CA3 pyramidal cells promotes mossy fiber pathfinding in the distal parts of the axons. (A) The expression viruses, including the CaMKII promoter were injected locally in the CA3 cell layer (green circle). Biocytin crystals were placed on the granule cell layer (pink circle) to visualize mossy fibers. (B) In nontreated control slices, mossy fibers visualized by the biocytin labeling (magenta) were fasciculated, and CA3 cells infected with mock viruses were identified by the co-expression of Venus (green). (C and D) K252a-treated slices with mock (C) or BDNF (D) expression are shown in high magnification images of the CA3c (2: solid box in I) or CA3a (3: dotted box in I) area. D shows abnormal distribution of mossy fibers in the CA3c area; these fibers began to accumulate in the CA3b area, which contained pyramidal cells overexpressing BDNF (green), and fasciculated tightly in the SL of the CA3a area. (E and F) Mossy fiber distribution estimated by biocytin labeling intensity in the CA3c $(E)$ and CA3a $(F)$ regions. $* P<0.05$ and $* *$, $P P<0.01$; Tukey's test after analysis of variance $(n=9$ slices obtained from 4 independent experiments). SR: stratum radiatum, SP: stratum pyramidale, and SO: stratum oriens.

cadherin-deficient mice have abnormal mossy fiber projection might be consistent with our hypothesis of the underlying mechanism $[25,26]$.

Alternatively, BDNF might induce the activation of receptors for repulsive guidance factors secreted from subregions other than the SL, such as the stratum radiatum and stratum pyramidale. Semaphorin 3s [27], Semaphorin 6A [28], and Slit-2 [29] function as repellents for mossy fibers. BDNF may act as a key regulator of other molecules by inducing and modulating their function.

The activity-dependent nature of BDNF [30] may be fundamentally associated with its neurobiologic functions. Interestingly, Danzer et al. (2004) showed that BDNF immunoreactivity is detected in mature presynaptic boutons of mossy fibers, and that the number of BDNF-rich presynaptic boutons is increased by pilocarpine-induced neuronal activity [7]. In our overexpression experiments, the artificially expressed BDNF would mimic that in mature mossy fiber terminals, thus it is likely that endogenous BDNF has a paracrine effect on newly generated fibers. It might be possible that the pathfinding effect of BDNF is involved in the activity-dependent plasticity underlying memory mechanisms. It would not, however, directly and immediately contribute to these mechanisms because the time course of mossy fiber pathfinding examined in this study (over several days) appears to be too long and newly-originated mossy fibers require 2.5 weeks to mature in adult mice [31]. Rather, the effect of BDNF may be as a signal for new fibers to fasciculate and extend further into the SL to form synapses with neurons that are far from active BDNF-expressing synapses. This view is supported by our finding that the passing fibers did not form obvious synaptic varicosities on any of the BDNFexpressing CA3 neurons (Fig. 4D). This mechanism would ensure the emergence of new independent dentate gyrus-CA3 circuits, which are hypothetically required to effectively encode information similar to, but distinct from, the preexisting circuits [32]. Dysregulation would 
cause information overwriting, which might be a clue to why schizophrenia has been related to BDNF reduction $[33,34]$. Recent suggestions that the etiology of schizophrenia may be due to adult neurogenesis [35] and subsequent mossy fiber guidance [36] seem to be consistent with this hypothesis.

\section{Conclusion}

Our findings are the first to clarify the role of BDNF in mossy fiber pathfinding; BDNF functions not as an attractant cue but as a regulator, possibly acting in a paracrine manner. This effect of BDNF may be as a signal for new fibers to fasciculate and extend further to form synapses with neurons that are far from active BDNF-expressing synapses. This mechanism would ensure the emergence of new independent dentate gyrus-CA3 circuits by the axons of new-born granule cells.

\section{Methods \\ Organotypic cultures of hippocampal slices}

Entorhino-hippocampal slices (300 $\mu \mathrm{m}$ thick) were prepared as previously described [9]. In some slices, the mossy fibers were cut with a scalpel after 4 DIV [37]. Slices were cultured using a membrane interface technique (Millicell-CM, Millipore, Bedford, MA) [38]. Cultures were fed $1 \mathrm{ml}$ of culture medium consisting of $50 \%$ minimal essential medium (Sigma, St. Louis, MO), 25\% horse serum (Cell Culture Lab, Cleveland, $\mathrm{OH}$ ), and 25\% Hanks' balanced salt solution containing $25 \mathrm{mM}$ glucose, 50 units $\mathrm{ml}^{-1}$ penicillin $\mathrm{G}$, and $100 \mu \mathrm{g} \mathrm{ml}^{-1}$ streptomycin, and maintained in a humidified incubator at $37^{\circ} \mathrm{C}$ in $5 \%$ $\mathrm{CO}_{2}$. The medium, with or without K252a (Wako, Osaka, Japan), was changed every 3.5 days.

\section{Immunohistochemistry and histology}

Cultured hippocampal slices were immersed in $4 \%$ paraformaldehyde at $4^{\circ} \mathrm{C}$ for $4 \mathrm{~h}$ and treated with $0.3 \%$ Triton $\mathrm{X}-100$ for $12 \mathrm{~h}$. After a 1-h incubation in 5\% goat serum at room temperature, rabbit anti-GFP antibody (1:1000; Molecular Probes, Eugene, OR) or anti-BDNF antibody $(0.5 \mu \mathrm{g} / \mathrm{ml}$, a generous gift from Amgen) in phosphate buffered saline (PBS) containing $2 \%$ goat serum was applied at $4{ }^{\circ} \mathrm{C}$ for $24 \mathrm{~h}$ followed by Alexa Fluor 488 goat anti-rabbit secondary antibody (1:500, Molecular Probes) for 4 to $6 \mathrm{~h}$, or biotinylated anti-rabbit secondary antibody (Vector Laboratories, Burlingame, CA) for $1 \mathrm{~h}$ at room temperature. To visualize Venus signals in mossy fibers, the TSA fluorescein system (PerkinElmer Life, Boston, MA) was used with 1-h incubation in avidin-biotin complex solution (Vector Laboratories) following treatment with anti-GFP antibody and quenching of endogenous peroxidase activity with $\mathrm{H}_{2} \mathrm{O}_{2}(0.3 \%)$ for $20 \mathrm{~min}$.

For biocytin labeling, biocytin crystals were placed on the granule cell layer of cultured slices $4 \mathrm{~h}$ before fixation.
These slices were fixed and permeabilized as for immunohistochemistry, and finally incubated with $10 \mu \mathrm{g} / \mathrm{ml}$ Texas Red-X-conjugated streptavidin (Molecular Probes) in a dark room at room temperature for $4 \mathrm{~h}$. For Nissl staining, slices were immersed in PBS containing 4\% paraformaldehyde for $24 \mathrm{~h}$, washed three times with PBS, treated with $0.1 \%$ Triton-X-100 for $60 \mathrm{~min}$, washed, and then incubated with NeuroTrace fluorescent Nissl (1:100 dilution; Molecular Probes) for $6 \mathrm{~h}$ at room temperature, followed by three rinses with PBS. All fluorescence signals were observed using a MRC-1000 confocal imaging system (Bio-Rad) with a $20 \times$ objective lens. Mossy fiber distribution was assessed by analyzing the EGFP or Venus signal ratio in each CA3 subregion. The average intensities of the fluorescent signals were quantified in five randomly selected areas $(10 \mu \mathrm{m} \times 10 \mu \mathrm{m})$ of each subregion. The subregions were defined on the basis of the distance from the stratum pyramidale (layer of soma), i.e., the SL is the region within $70 \mu \mathrm{m}$ from the stratum pyramidale, the stratum radiatum is the region above the $\mathrm{SL}$, and the stratum oriens is beyond the stratum pyramidale. The signal intensity was normalized using the sum of the raw intensities of all four CA3 subregions.

\section{Construction of the BDNF-expressing lentivirus vector}

To produce the cDNA coding for Venus, a brighter GFP derivative was provided as a kind gift from Dr. Miyawaki [39] and modified by PCR. The P2A sequence, a porcine teschovirus-1-derived $2 \mathrm{~A}$ peptide sequence, includes a $2 \mathrm{~A}$ consensus signal, D (V/I) EXNPG-P. The 2A signal is associated with a ribosomal skip in the peptide-bond formation between the glycine residue and the following proline residue [16].

BDNF cDNA capped with the Kozak sequence was connected in-frame with the Venus-P2A sequence through the BamHI site. The resultant BDNF was logically capped by PGST peptide at the N-terminus and the functionality of the secretion signal was confirmed experimentally (Fig. 2A2). The final BDNF protein was tagged with human cMyc peptide, QKLISEEDLNGAA at the C-terminus, and its activity has been confirmed [40]. The control mock virus plasmid has a stop codon immediately downstream of the BamHI site.

\section{Lentivirus preparation}

A lentiviral vector, FCGW, was a generous gift from Dr. P.V. Osten [14]. Lentiviruses were produced by HEK293T cells co-transfected with the expression vector $(3 \mu \mathrm{g})$ and three helper plasmids in a mixed package ( $9 \mu \mathrm{g}$; Invitrogen) using Lipofectamine 2000 (36 $\mu$ l per 10 -cm culture dish). The medium was changed once after 18 to $24 \mathrm{~h}$. Seventy-two hours after transfection, the medium was spun at $780 \times g$ for $15 \mathrm{~min}$, passed through a $0.45-\mu \mathrm{m}$ filter and centrifuged at $83,000 \times g$ for $90 \mathrm{~min}$, then the pel- 
let was resuspended in $100 \mu \mathrm{l}$ medium. The final titer was approximately $10^{8} \mathrm{PFU} / \mathrm{ml}$. Dissociated hippocampal cultures were exposed to the final suspension and then analyzed by immunocytochemistry for EGFP.

\section{Microinjection of vector suspension into the hippocampal slice cultures}

Micropipettes made from glass capillaries were autoclaved and the tips were broken to obtain a diameter of approximately $0.5 \mu \mathrm{m}$. For each experiment, a pipette was filled with a few microliters of lentiviral-vector suspension and placed directly over the cell layer using a micromanipulator (Narishige, Tokyo, Japan) and microejected using a brief (10-20 ms) pulse of compressed $\mathrm{N}_{2}$ gas via a Picoinjector (PLI-100; Narishige; 3.5-4.0 p.s.i). The suspension that was successfully delivered onto the slice was visually confirmed under the microscope. The BDNF virus or mock virus infection procedures were performed soon after the slices were prepared. Because lentivirus-mediated gene delivery expression plateaus $4 \mathrm{~d}$ after virus infection (data not shown), mossy fibers were cut once at 4 DIV. After the incision, a submaximal dose of K252a (100 nM) was applied and left in place for 1 week, during which mossy fiber regeneration was allowed to proceed [41].

\section{Statistics}

Data are expressed as means \pm SEM values. Tests of variance homogeneity, normality, and distribution were performed to ensure that the assumptions required for a standard parametric ANOVA were satisfied. Statistical analysis was performed by Student's $t$-test for two pairwise comparisons and one-way repeated-measures ANOVA and post hoc Tukey's test for multiple pair-wise comparisons. Significance was set at the $P<0.05$ level.

\section{Competing interests}

The authors declare that they have no competing interests.

\section{Authors' contributions}

MT performed all experiments except as otherwise noted with his original ideas of experimental details and wrote the manuscript draft. NT contributed on making a part of viral vector construct. TI carried out the expression in HEK and immunobloting. YI set up and RK developed slice culture experimental system. NM coordinated experimental environment as a professor. YI, RK and NM partly participated in the supervision of the work. MKY is conceived of research design, constructed the plasmid inserts for virus, wrote the manuscript and supervised. All authors helped to draft the manuscript.

\section{Additional material}

\section{Additional file 1}

Endogenous BDNF was expressed primarily along the mossy fiber pathways in cultured hippocampal slices, as observed in brain sections. Merged images of hippocampal slices stained (C, merged) with both Nissl staining of neurons (B) and BDNF immunohistochemistry (A). BDNF was highly expressed in the SL (arrow) and the dentate hilus, which are the normal mossy fiber pathways. GCL: granule cell layer, PCL: pyramidal cell layer, and DH: dentate hilus.

Click here for file

[http://www.biomedcentral.com/content/supplementary/17566606-2-2-S1.tiff]

\section{Additional file 2}

Higher doses of K252a defasciculated the BDNF-overexpressing mossy fibers. We performed the same experiments as in the case of figure 3; however, we used higher doses [200 $\mathrm{nM}$ (A) and $300 \mathrm{nM}$ (B)] of K252a. Mossy-fiber distribution was analyzed by determining the intensity of coexpressed Venus in the CA3c area (left) and the CA3 a area (right). We observed a minor effect of the expressed BDNF at $200 \mathrm{nM}(\mathrm{A})$; however, the effect was much lower than that observed in case of $100 \mathrm{nM} \mathrm{K252a}$, suggesting that BDNF could overcome the effect of K252a at submaximal doses and that BDNF action on mossy fibers is dependent on Trk signaling. ${ }^{*} \mathrm{P}<0.05$ and ${ }^{*} \mathrm{P}<0.01 ;$ Tukey's test after analysis of variance $(n$ = 7-9 obtained from three independent experiments). SR: stratum radiatum, SP: stratum pyramidale and SO: stratum oriens.

Click here for file

[http://www.biomedcentral.com/content/supplementary/17566606-2-2-S2.tiff]

\section{Acknowledgements}

We thank Dr. Jeong-Ah Kim who tried and noticed the effect of K252a at first. We thank Amgen Inc. for providing the anti-BDNF antibody; Dr. P.V. Osten for the lentivirus vector FCGW; and Dr. A. Miyawaki for the Venus cDNA. This work was supported by Grants-in-Aid (19590060, 20019016 to M.K.Y.) from MEXT Japan.

\section{References}

I. Henze DA, Urban NN, Barrionuevo G: The multifarious hippocampal mossy fiber pathway: a review. Neuroscience 2000, 98:407-427.

2. Altman J: Are new neurons formed in the brains of adult mammals? Science 1962, 135: I I27-I I 28.

3. Kee N, Teixeira CM, Wang AH, Frankland PW: Preferential incorporation of adult-generated granule cells into spatial memory networks in the dentate gyrus. Nat Neurosci 2007, 10:355-362.

4. Tamura M, Koyama R, lkegaya Y, Matsuki N, Yamada MK: K252a, an inhibitor of Trk, disturbs pathfinding of hippocampal mossy fibers. Neuroreport 2006, 17:48|-486.

5. Conner JM, Lauterborn JC, Yan Q, Gall CM, Varon S: Distribution of brain-derived neurotrophic factor (BDNF) protein and mRNA in the normal adult rat CNS: evidence for anterograde axonal transport. J Neurosci 1997, 17:2295-23I3.

6. Yan Q, Rosenfeld RD, Matheson CR, Hawkins N, Lopez OT, Bennett $L$, Welcher AA: Expression of brain-derived neurotrophic factor protein in the adult rat central nervous system. Neuroscience 1997, 78:431-448.

7. Danzer SC, McNamara JO: Localization of brain-derived neurotrophic factor to distinct terminals of mossy fiber axons implies regulation of both excitation and feedforward inhibition of CA3 pyramidal cells. J Neurosci 2004, 24: I I346-I I 355. 
8. Kojima M, Takei N, Numakawa T, Ishikawa Y, Suzuki S, Matsumoto T, Katoh-Semba R, Nawa H, Hatanaka H: Biological characterization and optical imaging of brain-derived neurotrophic factor-green fluorescent protein suggest an activity-dependent local release of brain-derived neurotrophic factor in neurites of cultured hippocampal neurons. I Neurosci Res 200I, 64:I-10.

9. Koyama R, Yamada MK, Fujisawa S, Katoh-Semba R, Matsuki N, Ikegaya $Y$ : Brain-derived neurotrophic factor induces hyperexcitable reentrant circuits in the dentate gyrus. J Neurosci 2004, 24:72। $5-7224$

10. Scharfman HE, Goodman JH, Sollas AL, Croll SD: Spontaneous limbic seizures after intrahippocampal infusion of brain-derived neurotrophic factor. Exp Neurol 2002, 174:20I-2I4.

II. Kokaia Z, Zhao Q, Kokaia M, Elmér E, Metsis M, Smith ML, Siesjö BK, Lindvall $O$ : Regulation of brain-derived neurotrophic factor gene expression after transient middle cerebral artery occlusion with and without brain damage. Exp Neurol 1995, 136:73-88.

12. Qiao X, Suri C, Knusel B, Noebels JL: Absence of hippocampal mossy fiber sprouting in transgenic mice overexpressing brain-derived neurotrophic factor. I Neurosci Res 200I, 64:268-276.

13. Koyama R, Ikegaya Y: To BDNF or not to BDNF: that is the epileptic hippocampus. Neuroscientist 2005, I I:282-287.

14. Dittgen T, Nimmerjahn A, Komai S, Licznerski P, Waters J, Margrie TW, Helmchen F, Denk W, Brecht M, Osten P: Lentivirus-based genetic manipulations of cortical neurons and their optical and electrophysiological monitoring in vivo. Proc Natl Acad Sci USA 2004, I01: |8206-1821।.

15. Das KP, Chao SL, White LD, Haines WT, Harry GJ, Tilson HA, Barone S Jr: Differential patterns of nerve growth factor, brainderived neurotrophic factor and neurotrophin-3 mRNA and protein levels in developing regions of rat brain. Neuroscience 200I, 103:739-76I.

16. Donnelly ML, Luke G, Mehrotra A, Li X, Hughes LE, Gani D, Ryan MD: Analysis of the aphthovirus 2A/2B polyprotein 'cleavage' mechanism indicates not a proteolytic reaction, but a novel translational effect: a putative ribosomal 'skip'. J Gen Virol 2001, 82:1013-1025

17. Danzer SC, Crooks KR, Lo DC, McNamara JO: Increased expression of brain-derived neurotrophic factor induces formation of basal dendrites and axonal branching in dentate granule cells in hippocampal explant cultures. J Neurosci 2002, 22:9754-9763.

18. Tapley P, Lamballe F, Barbacid M: K252a is a selective inhibitor of the tyrosine protein kinase activity of the trk family of oncogenes and neurotrophin receptors. Oncogene 1992, 7:37|-38I.

19. Ernfors P, Kucera J, Lee KF, Loring J, Jaenisch R: Studies on the physiological role of brain-derived neurotrophic factor and neurotrophin-3 in knockout mice. Int J Dev Biol 1995, 39:799-807.

20. Otal R, Martinez A, Soriano E: Lack of TrkB and TrkC signaling alters the synaptogenesis and maturation of mossy fiber terminals in the hippocampus. Cell Tissue Res 2005, 3 I 9:349-358.

21. Futatsugi A, Nakamura T, Yamada MK, Ebisui E, Nakamura K, Uchida $\mathrm{K}$, Kitaguchi T, Takahashi-Iwanaga H, Noda T, Aruga J, Mikoshiba K: IP3 receptor types 2 and 3 mediate exocrine secretion underlying energy metabolism. Science 2005, 309:2232-2234.

22. Chen TJ, Gehler S, Shaw AE, Bamburg JR, Letourneau PC: Cdc42 participates in the regulation of $A D F / c o f i l i n$ and retinal growth cone filopodia by brain derived neurotrophic factor. jNeurobiol 2006, 66:103-114.

23. Li Y, Jia YC, Cui K, Li N, Zheng ZY, Wang YZ, Yuan XB: Essential role of TRPC channels in the guidance of nerve growth cones by brain-derived neurotrophic factor. Nature 2005, 434:894-898.

24. Nishiyama M, Hoshino A, Tsai L, Henley JR, Goshima $Y$, TessierLavigne M, Poo MM, Hong K: Cyclic AMP/GMP-dependent modulation of $\mathrm{Ca} 2+$ channels sets the polarity of nerve growthcone turning. Nature 2003, 423:990-995.

25. Bamji SX, Rico B, Kimes N, Reichardt LF: BDNF mobilizes synaptic vesicles and enhances synapse formation by disrupting cadherin-beta-catenin interactions. J Cell Biol 2006, 174:289-299.

26. Bekirov IH, Nagy V, Svoronos A, Huntley GW, Benson DL: Cadherin-8 and $\mathrm{N}$-cadherin differentially regulate pre- and post- synaptic development of the hippocampal mossy fiber pathway. Hippocampus 2008, 18:349-363.

27. hédotal A, Del Rio JA, Ruiz M, He Z, Borrell V, de Castro F, Ezan F, Goodman CS, Tessier-Lavigne M, Sotelo C, Soriano E: Semaphorins III and IV repel hippocampal axons via two distinct receptors. Development 1998, 1 25:4313-4323.

28. Suto F, Tsuboi M, Kamiya H, Mizuno H, Kiyama Y, Komai S, Shimizu M, Sanbo M, Yagi T, Hiromi Y, Chédotal A, Mitchell KJ, Manabe T, Fujisawa H: Interactions between Plexin-A2, Plexin-A4, and Semaphorin 6A Control Lamina-Restricted Projection of Hippocampal Mossy Fibers. Neuron 2007, 53:535-547.

29. Nguyen Ba-Charvet KT, Brose K, Marillat V, Kidd T, Goodman CS, Tessier-Lavigne M, Sotelo C, Chédotal A: Slit2-Mediated chemorepulsion and collapse of developing forebrain axons. Neuron 1999, 22:463-473.

30. Chen J, Kitanishi T, lkeda T, Matsuki N, Yamada MK: Contextual learning induces an increase in the number of hippocampal CAI neurons expressing high levels of BDNF. Neurobiol Learn Mem 2007, 88:409-4I5.

31. Zhao C, Teng EM, Summers RG Jr, Ming GL, Gage FH: Distinct morphological stages of dentate granule neuron maturation in the adult mouse hippocampus. J Neurosci 2006, 26:3-II.

32. Wiskott L, Rasch MJ, Kempermann G: A functional hypothesis for adult hippocampal neurogenesis: avoidance of catastrophic interference in the dentate gyrus. Hippocampus 2006, 16:329-343.

33. Ohba S, Ikeda T, Ikegaya Y, Nishiyama N, Matsuki N, Yamada MK: BDNF locally potentiates GABAergic presynaptic machineries: target-selective circuit inhibition. Cereb Cortex 2005, 15:291-298.

34. Pillai $\mathrm{A}$ : Brain-derived neurotropic factor/TrkB signaling in the pathogenesis and novel pharmacotherapy of schizophrenia. Neurosignals 2008, 16:183-193.

35. Yamasaki N, Maekawa M, Kobayashi K, Kajii Y, Maeda J, Soma M, Takao K, Tanda K, Ohira K, Toyama K, Kanzaki K, Fukunaga K, Sudo Y, Ichinose H, Ikeda M, Iwata N, Ozaki N, Suzuki H, Higuchi M, Suhara T, Yuasa S, Miyakawa T: Alpha-CaMKII deficiency causes immature dentate gyrus, a novel candidate endophenotype of psychiatric disorders. Mol Brain 2008, I:6.

36. Faulkner RL, Jang MH, Liu XB, Duan X, Sailor KA, Kim JY, Ge S, Jones EG, Ming GL, Song H, Cheng HJ: Development of hippocampal mossy fiber synaptic outputs by new neurons in the adult brain. Proc Natl Acad Sci USA 2008, 105: | 41 157-14162.

37. Koyama R, Yamada MK, Nishiyama N, Matsuki N, Ikegaya Y: Group II metabotropic glutamate receptor activation is required for normal hippocampal mossy fibre development in the rat. J Physiol 2002, 539:157-162.

38. Koyama R, Muramatsu R, Sasaki T, Kimura R, Ueyama C, Tamura M, Tamura N, Ichikawa J, Takahashi N, Usami A, Yamada MK, Matsuki N, lkegaya Y: A low-cost method for brain slice cultures. J Pharmacol Sci 2007, 104:191-194.

39. Nagai T, Ibata K, Park ES, Kubota M, Mikoshiba K, Miyawaki A: A variant of yellow fluorescent protein with fast and efficient maturation for cell-biological applications. Nat Biotechnol 2002, 20:87-90.

40. Ikeda T, Tamura N, Matsuki N, Yamada MK: Conserved role of brain-derived neurotrophic factor in Val66 Met: target-selective reinforcement of GABAergic synapses. Neuroreport 2006, I7:|847-|85I.

4I. Ikegaya Y, Koyama R, Yamada MK, Nishiyama N, Matsuki N: Rapid regrowth of hippocampal mossy fibres and preceding maturation of NMDA receptor-mediated neurotransmission. Eur J Neurosci 2002, I 5: 1859-1862. 